Supporting Information

\title{
Aggregation-Dependent Photoreactive Hemicyanine Assembly as a
}

\section{Photobactericide}

Tian Tian, ${ }^{a}$ Tingjuan Qian, ${ }^{a}$ Xinyu Sui, ${ }^{b}$ Qilin Yu, ${ }^{c}$ Yingxin Liu, ${ }^{a}$ Xinfeng Liu, ${ }^{* b}$ Yulan Chen, ${ }^{* a d}$ Yi-Xuan Wang ${ }^{* a d e}$ and Wenping Hu ${ }^{\text {ade }}$

a. Tianjin Key Laboratory of Molecular Optoelectronic Sciences, Department of Chemistry, School of Science, Tianjin University, Tianjin 300072, China

b. Division of Nanophotonics CAS Key Laboratory of Standardization and Measurement for Nanotechnology, CAS Center for Excellence in Nanoscience, National Center for Nanoscience and Technology Beijing 100190, China

c. Department of Microbiology, College of Life Sciences, Nankai University, Tianjin 300071, China

d. Collaborative Innovation Center of Chemical Science and Engineering (Tianjin), Tianjin 300072, P. R. China

e. Joint School of National University of Singapore and Tianjin University, Fuzhou International Campus, Tianjin University, Binhai New City, Fuzhou 350207, China.

*Corresponding Author

E-mail: liuxf@nanoctr.cn

E-mail: Yulan.chen@tju.edu.cn

E-mail: yx_wang@tju.edu.cn 
Table of contents

1. Materials and instruments 3

2. The characterization of aggregation mode 4-8

3. The characterization of photodecomposition products 9

$\begin{array}{ll}\text { 4. The characterization of photolytic process } & 10\end{array}$

5. The characterization of isopropanol influence 11

6. Reference 12 


\section{Materials and instruments}

Materials: trans-4-[4-(Dihexylamino) styryl]-1-methylpyridinium iodide (DHASPI) was synthesized in terms of reported literature. ${ }^{\mathrm{S} 1, \mathrm{~S} 2}$ trans-4-[4-(Dimethyl-amino) $^{-}$ styryl]-1-methylpyridinium iodide (DMASPI, from Sigma), sodium hyaluronate (HA, $\mathrm{MW}=110000$, from Bloomage Freda Biopharm), sodium dodecyl sulfate (SDS, from Sigma), cetyltrimethylammonium bromide (CTAB, from Aladdin), and 5,5-dimethyl1-pyrroline N-oxide (DMPO, from TCI) were commercial available and used as purchased. 1-Methylpyridinium iodide and 4-(dihexylamino)benzaldehyde were synthesized according to the procedures reported previously. ${ }^{\mathrm{S} 3}$

Instruments: UV-vis absorption spectra were obtained on a PerkinElmer Lambda 750 spectrophotometer at $25{ }^{\circ} \mathrm{C}$. Fluorescence spectra were recorded on a Hitachi model F-7000 spectrofluorometer. The solution was irradiated using a $300 \mathrm{~W}$ Xenon lamp with a band-pass filter at $500 \mathrm{~nm}$ (CEL-HXF300, optical density: $\left.10 \mathrm{~mW} / \mathrm{m}^{2}\right) .{ }^{1} \mathrm{H}$ NMR spectra were recorded on a Bruker ADVANCE 400 at $25^{\circ} \mathrm{C}$. The electrospray ionization mass spectra (EI-MS) were recorded on a SHIMADZU GCMS-QP2010 SE. Dynamic light scattering (DLS) was measured using NanoBrook 173 plus. High resolution imaging of the aggregates was performed using a Hitachi S-4800 cold field emission scanning electron microscope (FE-SEM). HR-TEM was carried out on a JEOL JEM-2100F electron microscope with a LaB6 filament operated at $200 \mathrm{kV}$. Electron paramagnetic resonance (EPR) spectra were obtained using EMX-plus 6/1 (Bruker; Western Seoul Center of KBSI). Femtosecond transient absorption measurements were conducted with a temporal resolution of $\sim 120 \mathrm{fs} t$ on a commercial femtosecond TAS system (HELIOS, Ultrafast Systems). The pump fluence was attenuated to $\sim 12 \mu \mathrm{J} \mathrm{cm}^{-2}$ with two variable neutral density filter. The probe light was get where a small fraction of the $800 \mathrm{~nm}$ output from the Astrella was fed to a sapphire crystal in the HELIOS for generating the white light continuum (WLC). 


\section{The characterization of aggregation mode}

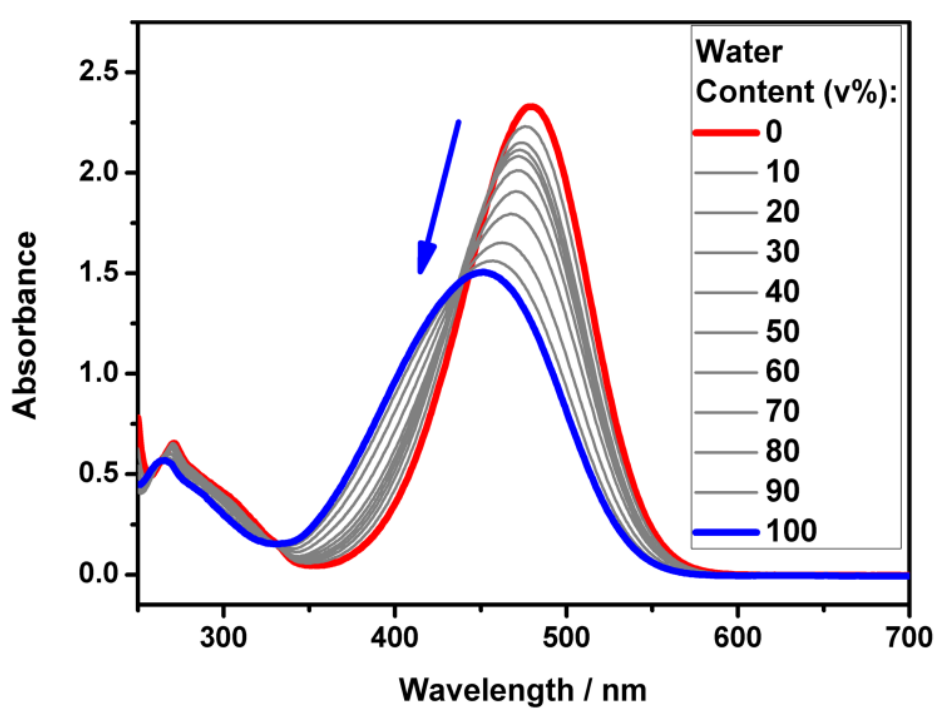

Figure S1. UV-vis absorption spectra of DMASPI $(0.05 \mathrm{mM})$ in EtOH/water mixtures with varying compositions at $25^{\circ} \mathrm{C}$.

(a)



Monomeric DHASPI in water (b)

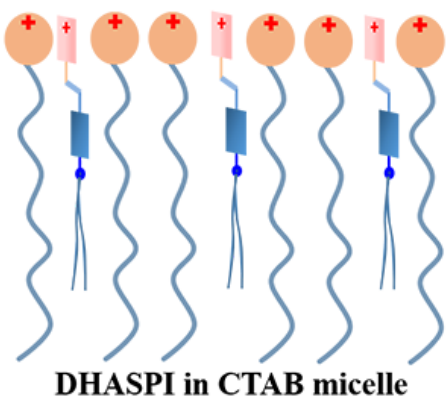

(d)

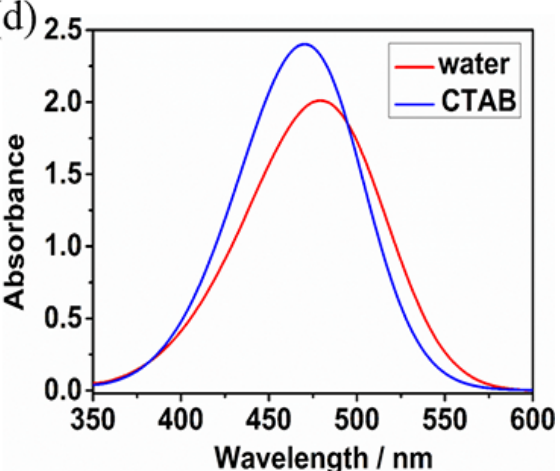

Figure S2. Schematic of DHASPI in (a) in the monomer state, (b) in CTAB micelle, and (c) in the aggregation state. (d) UV-vis absorption spectra for DHASPI (0.05 mM) with CTAB (5 mM), and DHASPI assembly $(0.05 \mathrm{mM})$ in water. 


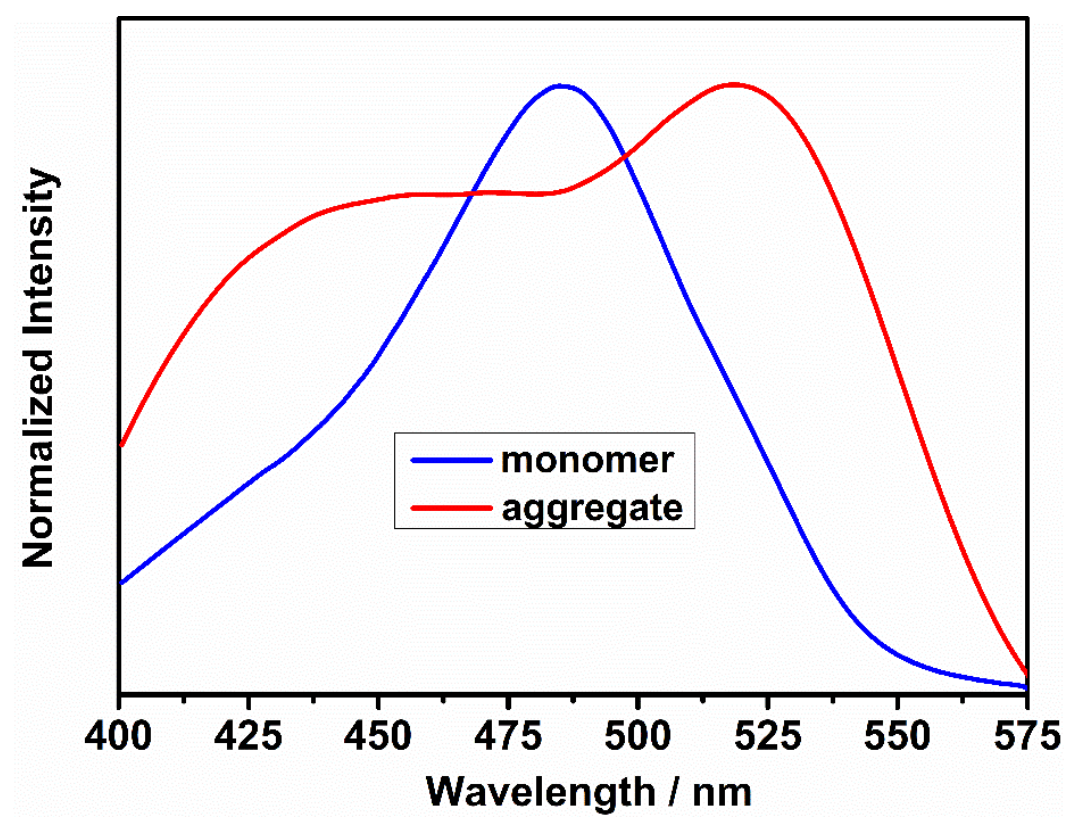

Figure S3. Excitation spectra of DHASPI in the states of monomer $\left(0.1 \mu \mathrm{M}, \lambda_{\mathrm{em}}=630\right.$ $\mathrm{nm})$ and aggregate $\left(50 \mu \mathrm{M}, \lambda_{\mathrm{em}}=630 \mathrm{~nm}\right)$ in water.

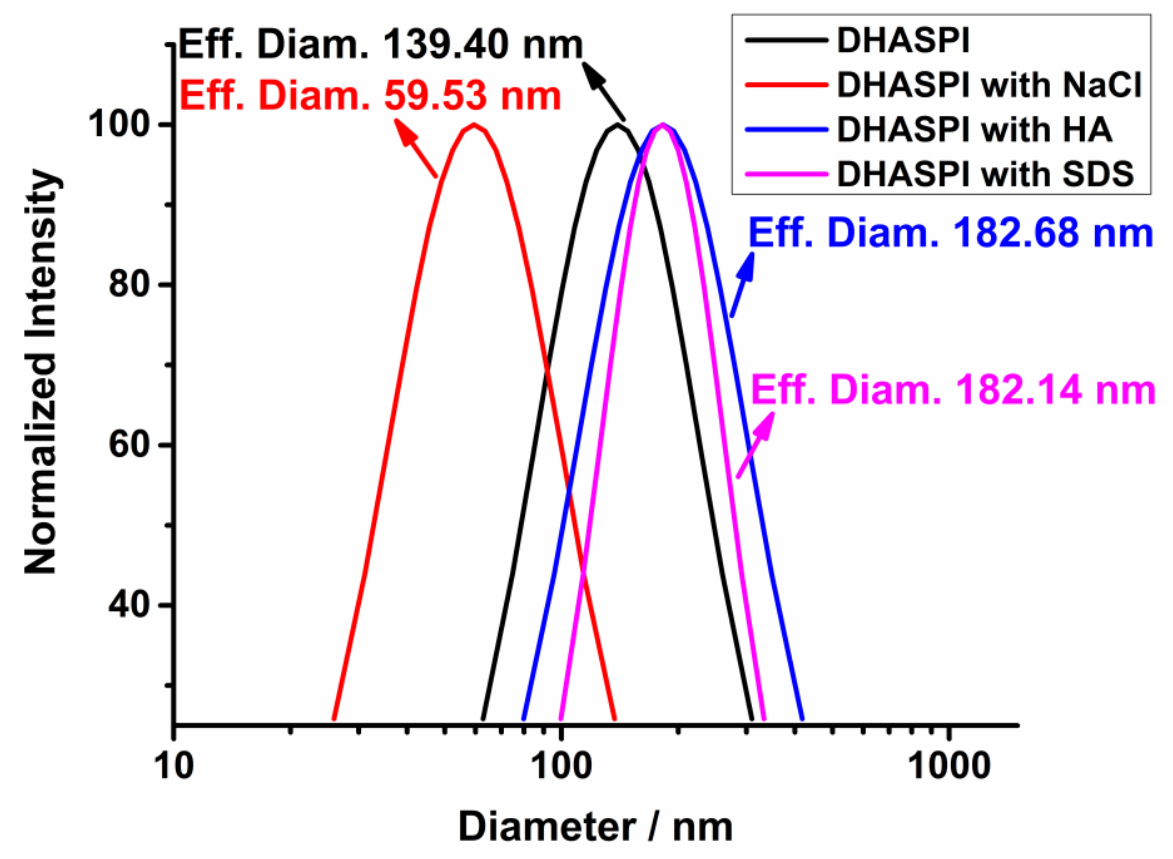

Figure S4. DLS data of the DHASPI assembly, DHASPI-NaCl assembly, DHASPI-HA assembly and DHASPI-SDS assembly in water at $25^{\circ} \mathrm{C}$. 
(a)

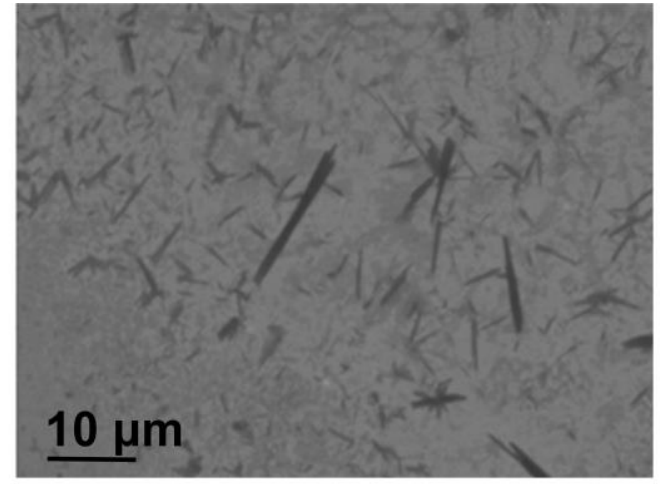

(b)

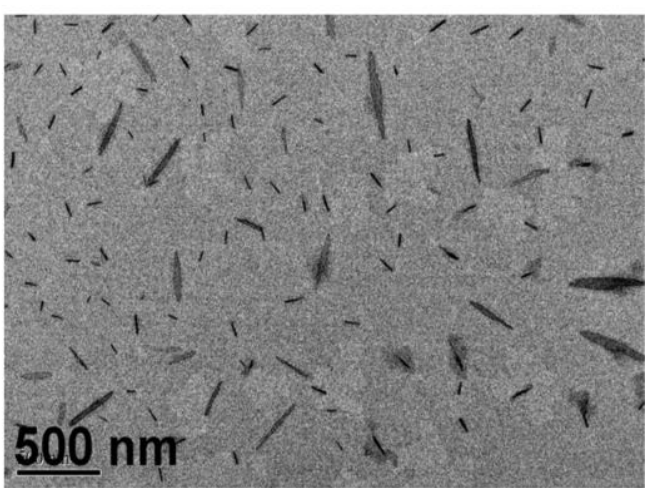

Figure S5. (a) SEM and (b) high-resolution TEM images of DHASPI assembly.

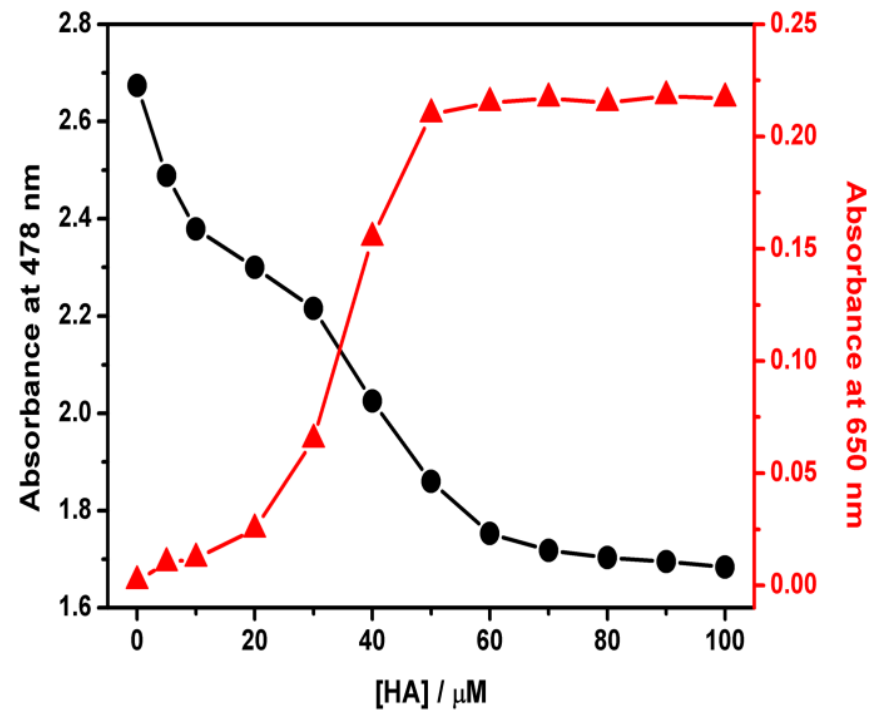

Figure S6. Dependence of the absorbance at $478 \mathrm{~nm}$ or $650 \mathrm{~nm}$ on the HA concentration with a fixed DHASPI concentration of $0.07 \mathrm{mM}$ at $25^{\circ} \mathrm{C}$.
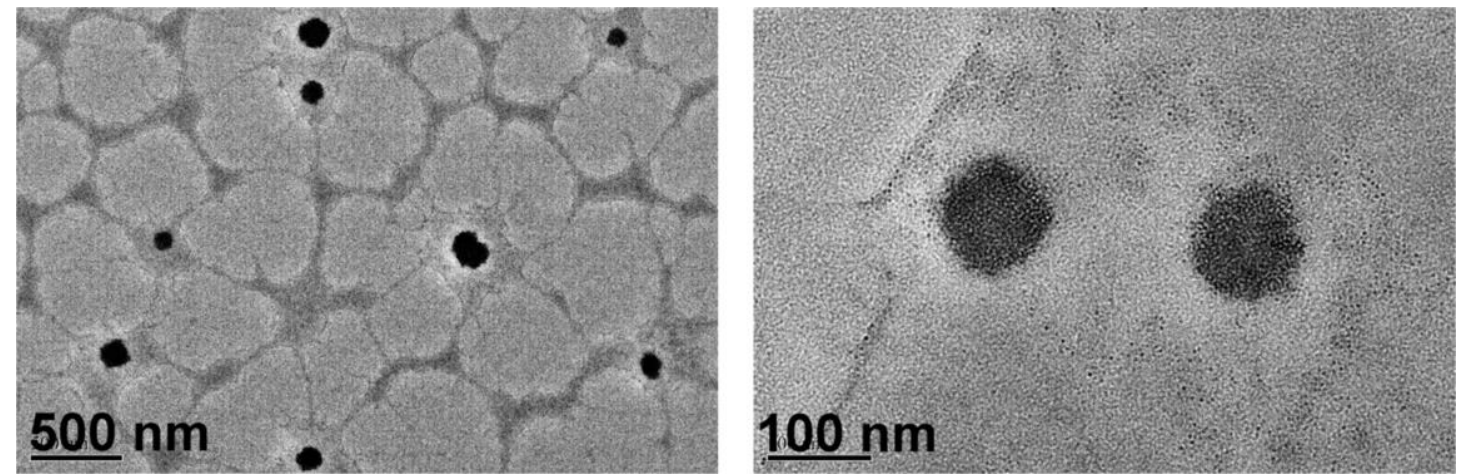

Figure S7. High-resolution TEM images of DHASPI-HA assembly. 


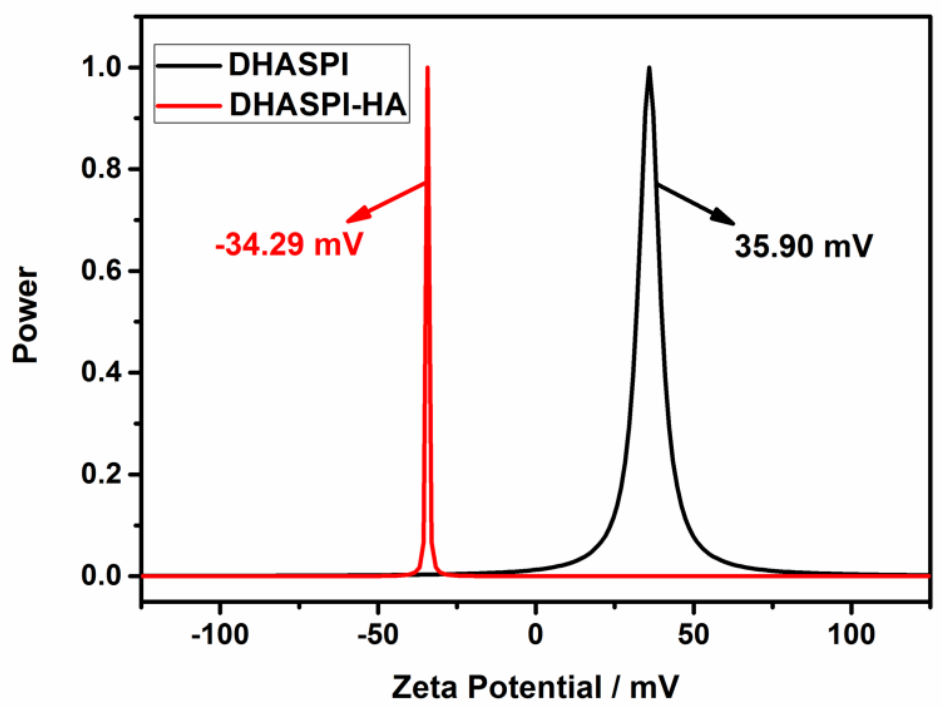

Figure S8. $\zeta$ potential data of the DHASPI in the absence and presence of HA at $25^{\circ} \mathrm{C}$.

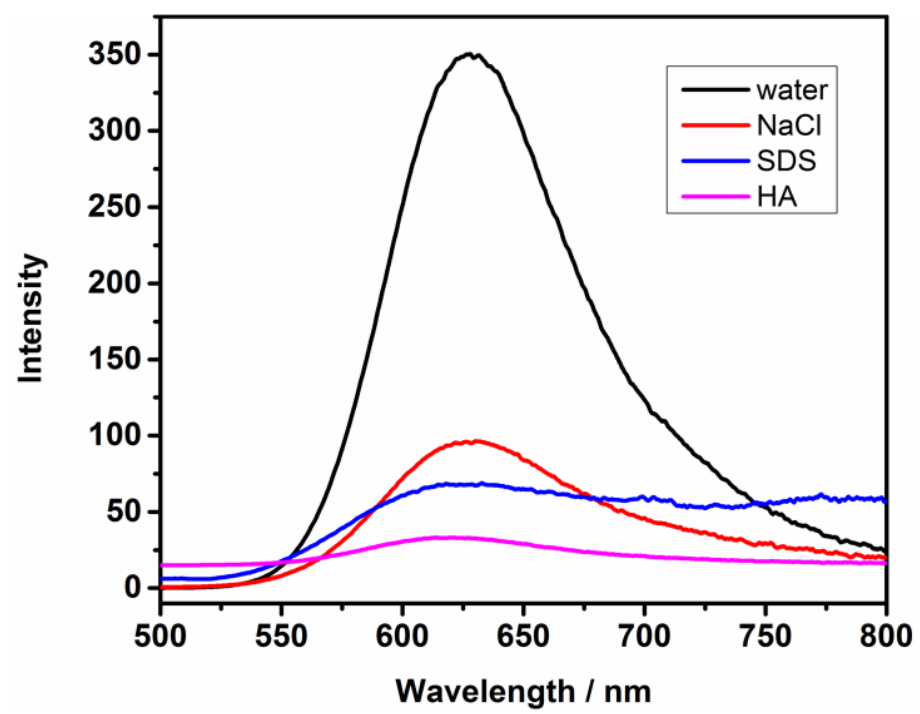

Figure S9. Fluorescence spectra of DHASPI assembly, DHASPI assembly in the presence of $\mathrm{NaCl}(100 \mathrm{mM})$, DHASPI-HA assembly, and DHASPI-SDS assembly at $25^{\circ} \mathrm{C}$. 

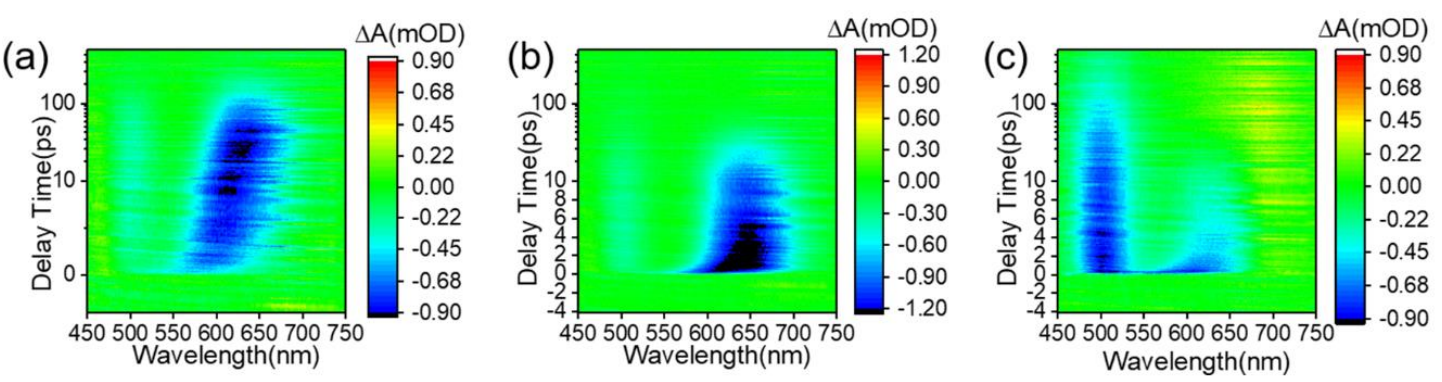

Figure S10. contour plot of Pump-probe absorption spectroscopy of DHASPI in (a) $\mathrm{EtOH},(\mathrm{b})$ water, and (c) $\mathrm{NaCl}$ solution $(\lambda \mathrm{ex}=400 \mathrm{~nm})$.


Figure S11. Decay kinetics recorded at (a) $510 \mathrm{~nm}$ and (b) $620 \mathrm{~nm}$ with a linear scale for the first picoseconds and log scale for the higher times. 


\section{The characterization of photodecomposition products}

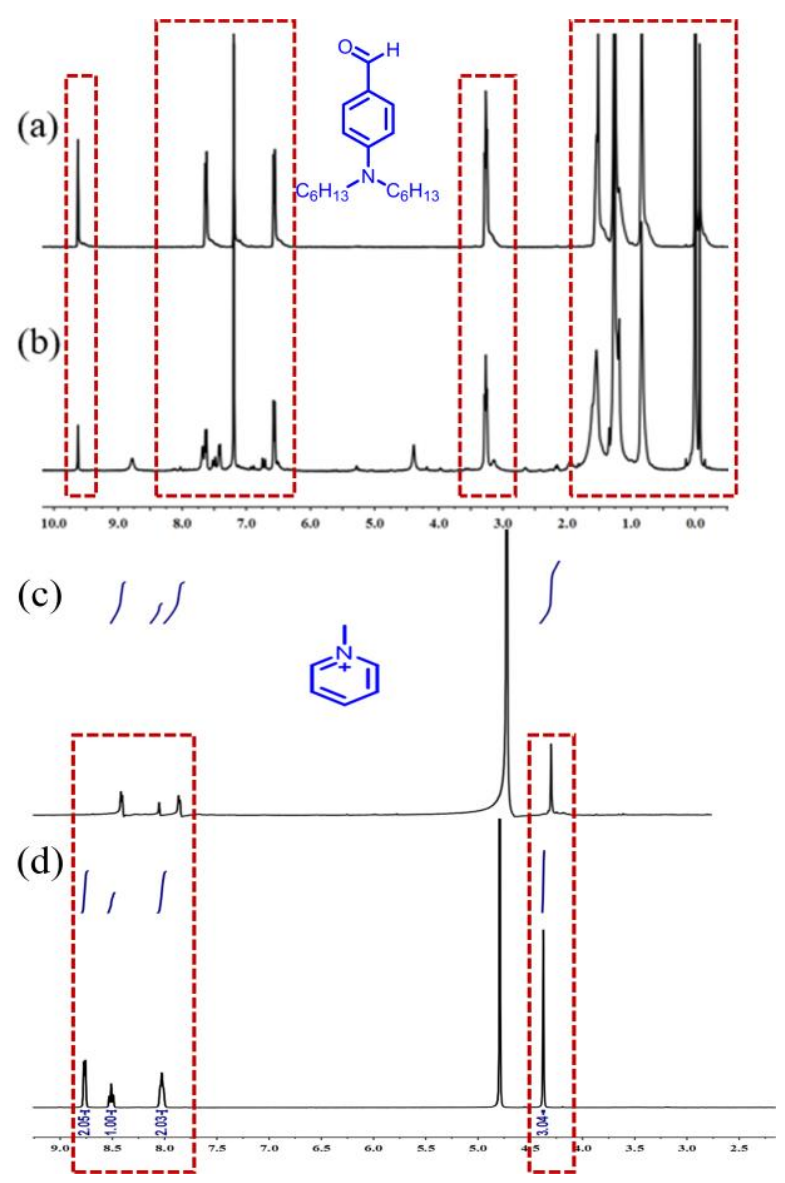

Figure S12. ${ }^{1} \mathrm{H}$ NMR spectra of (a) 4-(dihexylamino)benzaldehyde, and (b) the photolytic product of DHASPI assembly in organic phase in $\mathrm{CDCl}_{3} .{ }^{1} \mathrm{H}$ NMR spectra of (c) the photolytic product of DHASPI assembly in water phase, and (d) 1methylpyridinium iodide in $\mathrm{D}_{2} \mathrm{O}$.
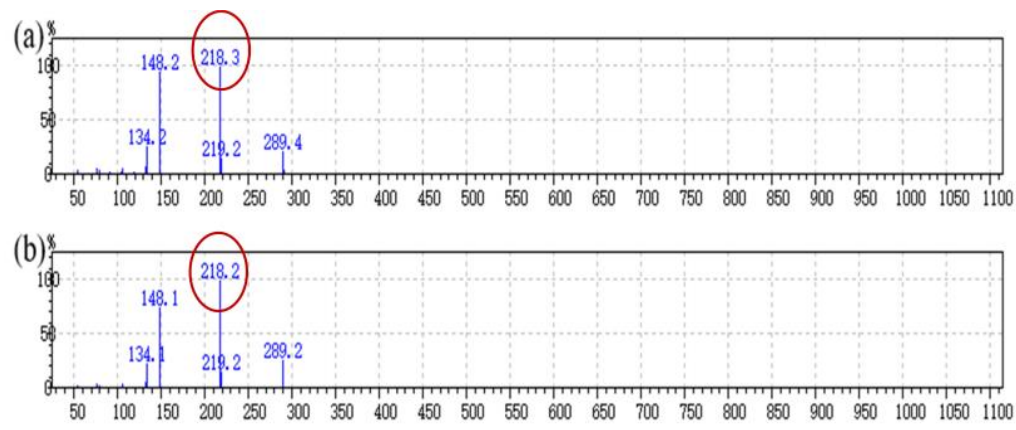

Figure S13. GC-MS spectra of (a) the photolytic product of DHASPI assembly in organic phase and (b) 4-(dihexylamino)benzaldehyde. 


\section{The characterization of photolytic process}
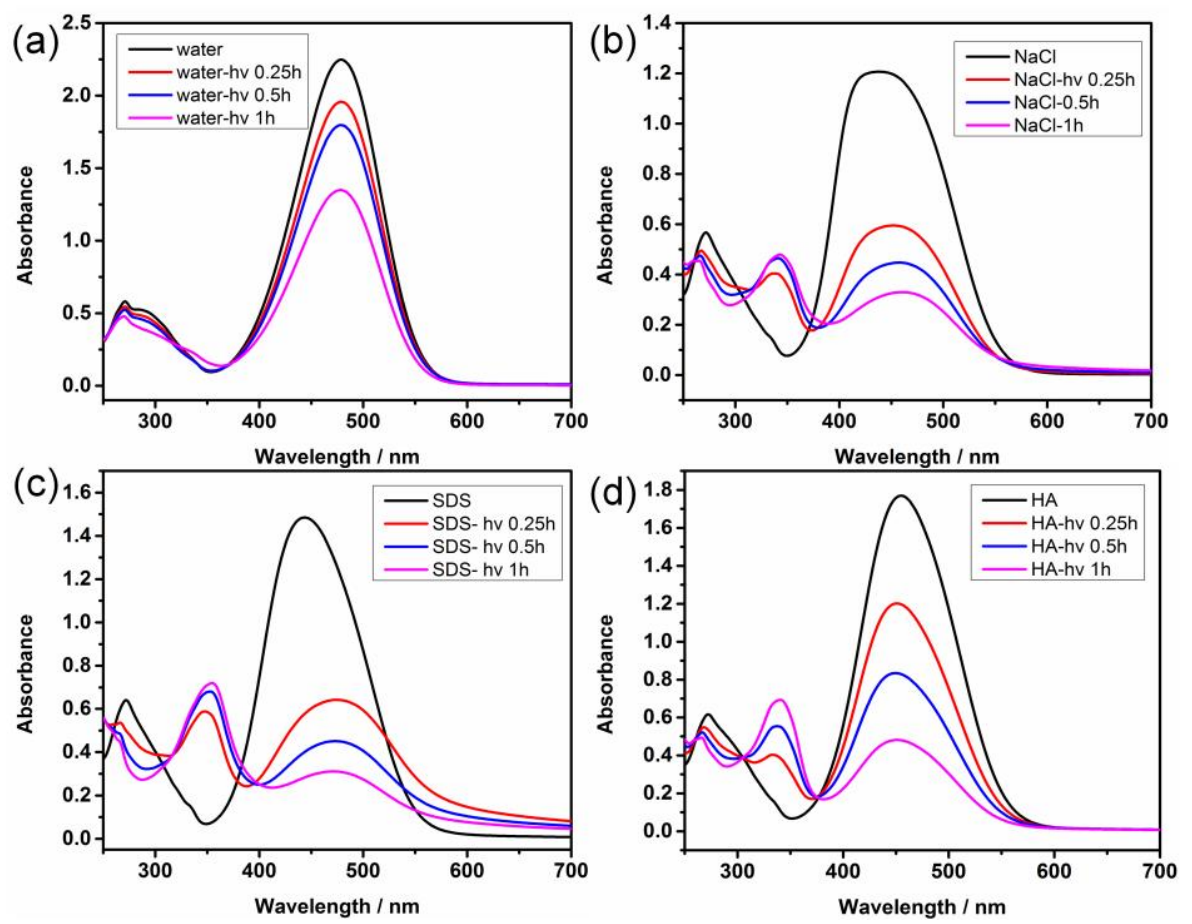

Figure S14. UV-vis absorption spectra of (a) DHASPI (0.05 mM), (b) DHASPI (0.05 $\mathrm{mM})$ in $\mathrm{NaCl}(100 \mathrm{mM})$ solution, (c) DHASPI $(0.05 \mathrm{mM})$ with SDS $(0.05 \mathrm{mM})$ and $(\mathrm{d})$ DHASPI-HA assembly $(0.05 \mathrm{mM})$ upon light irradiation for different periods of time at $25^{\circ} \mathrm{C}$.


Figure S15. (a) UV-vis absorption spectra of DHASPI $(0.05 \mathrm{mM})$ in EtOH, and DHASPI $(0.05 \mathrm{mM})$ with CTAB $(5 \mathrm{mM})$ before and after light irradiation for $1 \mathrm{~h}$ at $25^{\circ} \mathrm{C}$. (b) Fluorescence spectra of DHASPI assembly (0.05 mM), DHASPI (0.05 mM) with CTAB ( $5 \mathrm{mM})$, and DHASPI $(0.05 \mathrm{mM})$ in EtOH at $25^{\circ} \mathrm{C}$. 


\section{The characterization of isopropanol influence}
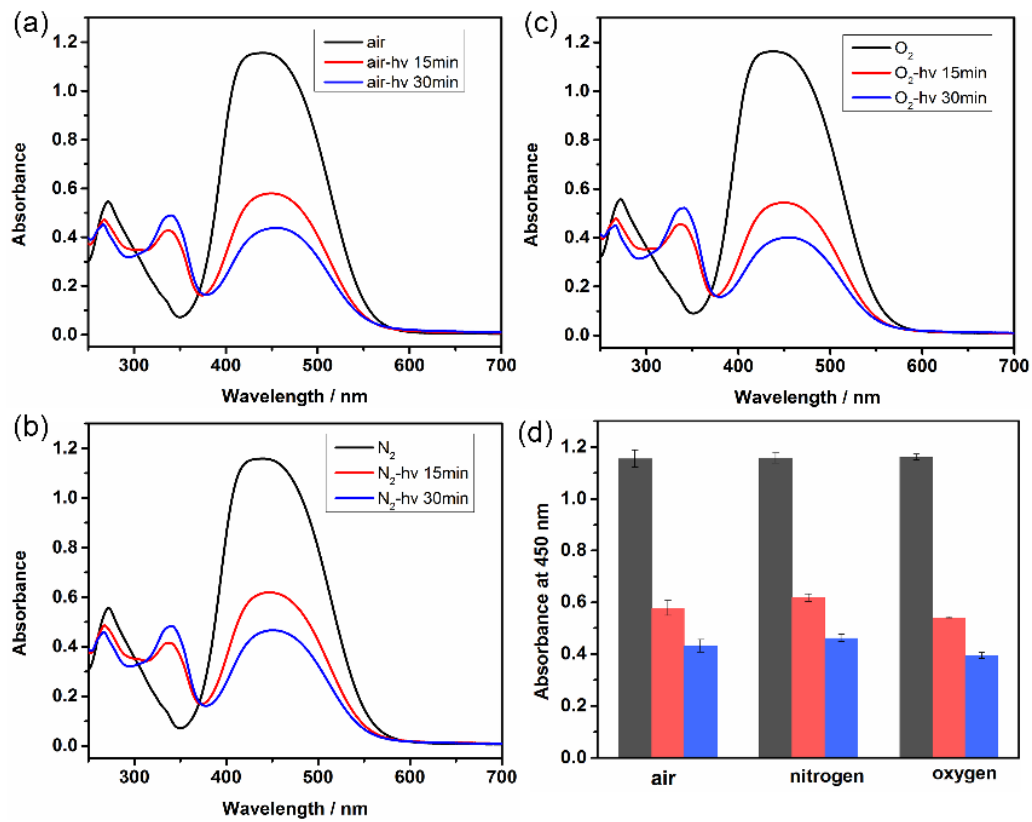

Figure S16. UV-vis absorption spectra of DHASPI in $\mathrm{NaCl}(100 \mathrm{mM})$ solution before and after irradiation at $25^{\circ} \mathrm{C}$. The experiments were carried out (a) under air, (b) after inletting oxygen, or (c) after inletting nitrogen. (d) Absorbance change of DHASPI at $450 \mathrm{~nm}$.

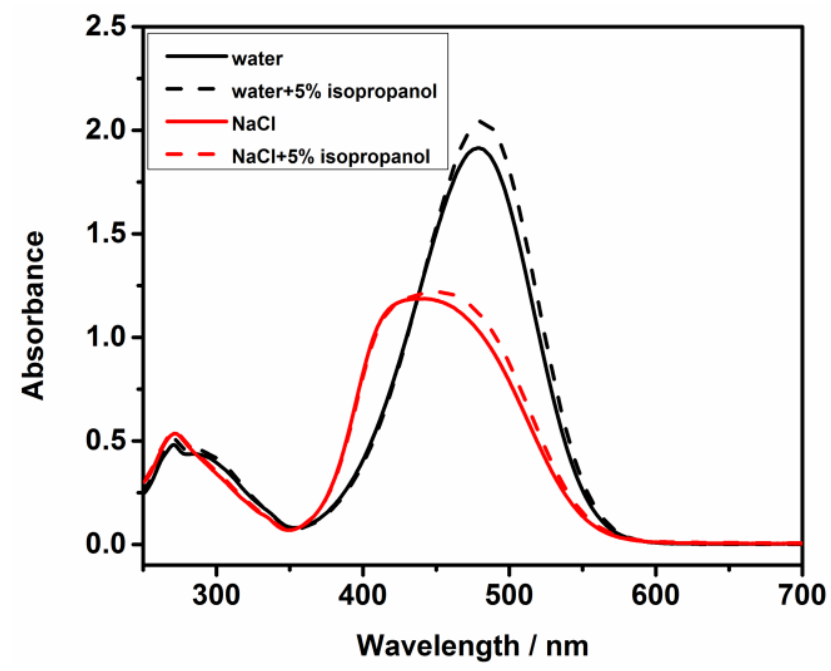

Figure S17. UV-vis absorption spectra of DHASPI $(0.05 \mathrm{mM})$ and DHASPI $(0.05 \mathrm{mM})$ with $\mathrm{NaCl}(100 \mathrm{mM})$ in the absence and presence of isopropanol. 


\section{Reference}

S1. Wang, L. Y.; Zhang, X. G.; Shi, Y. P.; Zhang, Z. X. Microwave-assisted solvent-free synthesis of some hemicyanine dyes. Dyes Pigments 2004, 62, 21-25.

S2. Li, F.; Gao, N.; Xu, H.; Liu, W.; Shang, H.; Yang, W. J.; Zhan, M. Relationship between Molecular Stacking and Optical Properties of 9,10-Bis((4-N,Ndialkylamino)styryl) Anthracene Crystals: The Cooperation of Excitonic and Dipolar Coupling. Chem. Eur. J. 2014, 20, 9991-9997.

S3. Daniel, J.; Martin, P.; Jiri, B.; Jan, M.; Miroslav, P.; Petr, S.; Kamil, K. Preparation and In Vitro Evaluation of Monoquaternary Inhibitors of Brain Cholinesterases. Lett. Org. Chem. 2009, 6, 500-503. 